\title{
Gestão do capital de giro das empresas do setor cerâmico catarinense: práticas administrativas
}

\author{
Luiz Henrique Debei Herling \\ Marcus Vinicius Andrade de Lima \\ Carlos Rogerio Montenegro de Lima \\ Mauricio Andrade de Lima
}

Mestre em Administração. Universidade Federal de Santa Catarina (UFSC) - Brasil. Ihherling@gmail.com Doutor em Engenharia de Produção. Universidade Federal de Santa Catarina (UFSC) - Brasil. marcus.lima@ufsc.br Doutor em Engenharia de Produção. Universidade do Sul de Santa Catarina (Unisul) - Brasil. calmontenegro@gmail.com Doutor em Engenharia de Produção. Universidade do Sul de Santa Catarina (Unisul) - Brasil. mauricio.lima@unisul.br

\section{RESUMO}

O presente estudo tem por objetivo analisar as práticas de capital de giro adotadas pelas empresas do setor cerâmico catarinense em relação à teoria financeira, buscando assim evidenciar se o modo de gestão praticado é condizente com a teoria financeira. Foram pesquisadas as empresas do setor filiadas à ASULCER (Associação Sul Brasileira da Indústria Cerâmica para Revestimento) com coleta de dados por meio de questionário e entrevistas, sendo analisados os seus balanços e demonstrativos financeiros para mensuração de índices de gestão do capital de giro. Constatou-se que as empresas apresentam uma gestão de capital de giro planejada, executada por gestores com conhecimento sobre o tema, mas com diretrizes pouco definidas. Os gestores utilizam o ferramental teórico disponível, mas os indicadores financeiros com relação à capacidade de pagamento não são saudáveis de uma maneira geral, e os indicadores operacionais apresentam certa homogeneidade.

Palavras-chave: Administração Financeira de Curto Prazo. Gestão do Capital de Giro. Setor Cerâmico Catarinense. Avaliação de Desempenho.

\section{Working capital management of firms of ceramic industry of Santa Catarina: administrative practices}

\begin{abstract}
The objective of this study is to analyze the working capital practices adopted by companies in the ceramic industry in Santa Catarina in relation to financial theory, in order to verify if the management practices are consistent with financial theory. Ceramic sector companies affiliated to ASULCER (Southern Brazilian Association of the Ceramic Industry for Coating) were investigated, with data collection through questionnaires and interviews, and its balance sheets and financial statements were analyzed for the measurement of working capital management indices. It was verified that the companies present a planned working capital management, executed by managers with knowledge on the subject, but with little defined guidelines. Managers use the available theoretical tools, but the financial indicators regarding the payment capacity are not generally healthy, and the operational indicators show some homogeneity.
\end{abstract}

Keywords: Short-Term Financial Management. Working Capital Management. Ceramic industry of Santa Catarina. Performance evaluation. 


\section{INTRODUÇÃO}

As atividades empresariais visam ao lucro e a perpetuar-se no mercado. Em um cenário globalizado, onde as empresas encaram a cada dia mais concorrentes, realizar uma gestão financeira eficiente é um ponto decisivo a ser trabalhado para que as empresas tenham êxito no alcance de seus objetivos.

Entre as crises econômicas enfrentadas no mundo contemporâneo, pode-se citar as crises de 1929, o choque do petróleo da década de 1970 e as recentes crises de 2008 e 2010. Segundo Assaf Neto (2010), as finanças corporativas incorporam em seu escopo a evolução da economia. Uma consequência disto é o tempo de recuperação das empresas frente às crises que se apresentam. Com a evolução dos mecanismos de gestão, o tempo de recuperação das organizações passa a ser cada vez menor, o que colabora de forma direta para a retomada e, após recuperar a estabilidade, o crescimento da economia.

A Gestão do Capital de Giro é um assunto relevante para os gestores financeiros que dedicam tempo e esforço significativos na busca de um equilíbrio ideal entre risco e retorno, rentabilidade e liquidez, a fim de criar valor para a empresa.

Carvalho e Schiozer (2012) investigaram os determinantes do estilo de condução da gestão financeira de curto prazo em micro e pequenas empresas (MPEs). Os dados obtidos por meio de um survey com dirigentes de 447 MPEs dos estados de Minas Gerais e São Paulo identificaram quatro estilos de gestão de capital de giro, que podem ser explicados por variáveis como idade, tamanho e lucratividade da firma. Os resultados foram comparados aos obtidos por pesquisa similar realizada com empresas do Reino Unido (HOWORTH; WESTHEAD, 2003), e mostrou diferenças importantes: (a) as empresas brasileiras revisam a maioria das rotinas de capital de giro com maior frequência que as britânicas; (b) as MPEs brasileiras ofertam menos crédito comercial que as britânicas. Essas diferenças podem ser explicadas, pelo menos em parte, pelo maior custo do financiamento bancário das firmas brasileiras em comparação com as britânicas.

Almeida e Eid Jr. (2014) analisaram o impacto da alavancagem financeira na relação entre o capital de giro e o valor da empresa, e como as restrições financeiras ao acesso ao financiamento afetam essa relação. Além disso, analisaram a relação entre capital de giro e valor da empresa. Utilizando uma amostra de empresas brasileiras listadas na BM\&FBOVESPA de 1995 a 2009, encontraram evidências para as seguintes conclusões: um real extra (R\$) de investimento em capital de giro é significantemente menor em média do que um real extra (R\$) de investimento em caixa; e, em média, o aumento do nível de capital de giro no início de um ano fiscal reduz o valor da empresa.

De acordo com Kroes e Manikas (2014), as políticas de fluxo de caixa de uma empresa que administra o capital de giro na forma de recebíveis de clientes, estoques e pagamentos em dinheiro aos fornecedores estão inexoravelmente ligadas às operações da empresa. Analisaram uma amostra longitudinal de oito trimestres de fluxo de caixa e dados de desempenho financeiro de 1233 empresas de manufatura. As análises descobriram que as mudanças na métrica amplamente utilizada do Ciclo de Conversão de Caixa (CCC) não se relacionam com mudanças no desempenho da empresa; entretanto, as mudanças na métrica menos utilizada de Ciclo de Caixa Operacional (CCO) estão significativamente associadas a mudanças no " $q$ " de Tobin. Esse exame de como as mudanças nas medidas específicas de fluxo de caixa se relacionam com mudanças no "q" de Tobin mostra que tanto as reduções de Contas a Receber (medida pelo Prazo Médio de Vendas - PMV) quanto as reduções no Estoque (medida pelo Prazo Médio de Estoques $[\mathrm{PME}]$ ) relacionam-se com melhorias no desempenho financeiro que persistem por vários trimestres.

Palombini e Nakamura (2012) analisaram os dados de 2.976 empresas brasileiras de capital aberto referentes ao período entre 2001 e 2008 e concluíram que o nível de dívidas, o tamanho da empresa e a taxa de crescimento podem afetar a gestão do capital de giro das empresas.

Banos-Caballero, Garcıa-Teruel e Martınez-Solano (2010) analisaram os determinantes do Ciclo de Conversão em Caixa (CCC) para pequenas e médias empresas. Verificaram que estas empresas têm um CCC meta ao qual tentam convergir e que tentam ajustar-se rapidamente a sua meta. Os resultados também mostram que este é mais longo para empresas mais antigas e empresas com fluxo de caixa maior. Em contraste, as empresas com mais oportunidades de crescimento e as empresas com maior alavancagem, investimento em ativos fixos e retorno sobre os ativos têm uma política de capital de giro mais agressiva.

A falta de compreensão do impacto da gestão do capital de giro sobre a rentabilidade, a falta de clareza sobre seus principais componentes, a falta de capacidade de gestão para planejar e controlar componentes de capital de giro pode levar à insolvência e falência (PALOMBINI; NAKAMURA, 2012).

A gestão inadequada do capital de giro foi apontada como um dos principais motivos para o fechamento de empresas de micro e pequeno porte no Brasil e as práticas de gestão financeira nas micro e pequenas empresas têm se 
mostrado incompletas e muitas vezes inexistentes, o que prejudica o desenvolvimento de uma forma geral, segundo dados do SEBRAE (2007).

Diante deste cenário e da representatividade do setor cerâmico na economia catarinense, da conjuntura econômica atual e da importância da gestão financeira nas organizações, a presente pesquisa tem por objetivo analisar as práticas de capital de giro adotadas pelas empresas do setor cerâmico catarinense em relação à teoria financeira, buscando assim evidenciar se o modo de gestão praticado é condizente com a teoria financeira.

\section{GESTÃO DO CAPITAL DE GIRO NA ADMINISTRAÇÃO FINANCEIRA DE CURTO PRAZO}

A seguir é exposto referencial teórico dos temas dessa pesquisa: administração financeira de curto prazo e gestão do capital de giro.

A gestão de curto prazo trata de ativos e passivos circulantes. No que tange aos ativos circulantes, são abordados a gestão do capital de giro que contempla os recursos alocados em ativos circulantes, a gestão do caixa, a gestão de contas a receber, de estoques, as fontes de financiamentos de curto prazo, a gestão de impostos, controles de tesouraria e os diversos relacionamentos com passivos circulantes no que tange à mão de obra (salários), fornecedores de matériaprima e insumos.

Pode-se ver, conforme a figura 1, o balanço patrimonial de uma organização com suas contas classificadas como circulantes e não circulantes.

Figura 1 - Balanço Patrimonial

\begin{tabular}{|l|l|}
\hline $\begin{array}{l}\text { Ativo Circulante (AC) } \\
\begin{array}{l}\text { Disponibilidades } \\
\text { Estores a Receber }\end{array}\end{array}$ & $\begin{array}{l}\text { Passivo Circulante (PC) } \\
\text { Fornecedores } \\
\text { Encargos e Salários } \\
\text { Empréstimos e Financiamentos }\end{array}$ \\
$\begin{array}{l}\text { Ativo Não Circulante (ANC) } \\
\begin{array}{l}\text { Realizável a Longo Prazo } \\
\text { Investimentos } \\
\text { Intangível }\end{array}\end{array}$ & \\
& \\
& \\
\end{tabular}

Fonte: Adaptado de Marion (2015)

O gestor financeiro enfrentará três tipos de decisão, conforme apresentado por Matias (2006): Decisão de Investimento; Decisão de Financiamento; Decisão de operações.

Sabe-se que o capital pode ser composto de recursos próprios (acionistas) ou de terceiros (instituições financeiras e outros fornecedores de capital). Nesse contexto, cada fonte de captação terá um custo diferenciado, e este é um grande desafio ao gestor. Avaliar quais as fontes de financiamento ideais para empresa é um ponto importante para a boa gestão financeira, ou seja, as menos onerosas.

Após os recursos estarem disponíveis, o gestor financeiro se depara com a necessidade de aplicá-los. Assim, surgem as decisões de investimento, que consistem em avaliar se o emprego dos recursos supera o seu custo de captação, e se trazem o retorno esperado de acordo com o planejamento.

Nos mercados de capitais perfeitos, as decisões de investimento são independentes das decisões de financiamento e, portanto, a política de investimento só depende da disponibilidade de oportunidades de investimento com um valor presente líquido positivo porque as empresas têm acesso ilimitado a fontes de financiamento externa e os recursos externos constituem um substituto perfeito para os recursos internos (MODIGLIANI; MILLER, 1958). Nessa situação, um CCC mais longo não teria custo de oportunidade, porque as empresas poderiam obter fundos externos sem problemas e a um custo razoável. No entanto, os financiamentos interno e externo não são substitutos perfeitos na prática. Financiamento externo, dívida ou novas emissões de ações, podem ser mais caros do que o financiamento interno devido às imperfeições do mercado. Nestas circunstâncias, as decisões de investimento e de financiamento de 
uma empresa são interdependentes e as empresas podem ter um CCC ótimo que equilibre custos e benefícios e maximize seu valor (BANOS-CABALLERO; GARCIA-TERUEL; MARTINEZ-SOLANO, 2010).

Operar uma empresa no âmbito financeiro é muito mais complexo do que parece, pois requer do gestor controles avançados. Em uma economia dinâmica, onde cada ponto dos custos reflete automaticamente na lucratividade da empresa, tomar as decisões corretas quanto à operação dos recursos é essencial.

Pode-se citar aqui os métodos de controle de estoques, métodos de controle de caixa, gestão do crédito, fontes de captação de recursos, onde estes itens são onerosos e requerem gestão eficiente a fim de não comprometer o resultado da empresa (ASSAF NETO, 2010; SANTOS, 2010; ROSS, WESTERFIELD; JAFFE, 2007).

O fluxo de caixa de uma empresa pode ser manipulado de três maneiras: (i) o tempo desde que os bens são vendidos até que a receita seja recebida pela empresa pode mudar; (ii) os níveis de estoques da empresa podem mudar; e (iii) o tempo que a empresa leva para pagar seus fornecedores pode mudar (KROES; MANIKAS, 2014).

$\mathrm{Na}$ gestão financeira de curto prazo, as decisões do gestor financeiro estarão inerentes às contas de Ativo Circulante e Passivo Circulante, como aponta Assaf Neto (2010). No ativo circulante (investimentos), o gestor terá decisões referentes ao controle das disponibilidades, da gestão de investimentos de curto prazo, estoques e contas a receber de curto prazo. No lado do passivo (financiamento) terá decisões referentes aos fornecedores a pagar no curto prazo, às despesas referentes a salários, encargos e demais contas que se encaixem no curto prazo da empresa.

Como o capital de giro é um componente importante do fluxo de caixa das operações e o fluxo de caixa das operações faz parte da estimativa dos fluxos de caixa livres, conclui-se que a gestão eficiente do capital de giro é relevante para qualquer empresa. Assim, pode-se afirmar que a gestão eficiente do capital de giro é uma parte fundamental da estratégia de qualquer empresa para criar valor para os acionistas (BANOS-CABALLERO; GARCIA-TERUEL; MARTINEZSOLANO, 2010; ALMEIDA, J. R.; EID Jr., 2014).

É necessário que se respeite o princípio da correspondência cronológica dos recursos ou das operações, ou seja, recursos de longo prazo financiando contas de longo prazo. Esta mesma estrutura deve atender ao curto prazo, ou seja, Passivo Circulante financiando o Ativo Circulante da empresa.

Por ser uma administração diária, Lemes Junior, Cherobim e Rigo (2016) afirmam que a gestão do curto prazo é realizada em todas as empresas. Porém, ao confrontar-se com a realidade, verifica-se que a gestão de capital de giro realizada nas empresas é feita de forma a resolver problemas que surgiram justamente em função da falta de planejamento e controle financeiro de curto prazo.

Outro ponto a ser destacado é que se as empresas adotassem métodos de controle de capital de giro aliados a outras ferramentas de gestão, a mortalidade de empresas no Brasil reduziria significativamente.

As dificuldades de capital de giro em uma empresa são devidas, principalmente, à ocorrência dos seguintes fatores: redução de vendas; crescimento da inadimplência; aumento das despesas financeiras; aumento de custos; alguma combinação dos quatro fatores anteriores. Na situação mais frequente, os problemas de capital de giro surgem como consequência de uma redução de vendas (ROSS, WESTERFIELD; JAFFE, 2007).

Segundo definição de Vieira (2005, p. 36), capital de giro é definido por "montante total investido no ativo circulante, representado por: caixa, bancos, aplicações financeiras, estoques e contas a receber de clientes".

Sua função, ainda segundo o autor, é a manutenção do equilíbrio financeiro como forma de garantir a continuidade da atividade operacional e propiciar condições adequadas que favoreçam a sua sobrevivência e crescimento. Em síntese, é honrar os compromissos assumidos, fazendo com que as contas não se atrasem. Para tal, é essencial uma programação eficiente de fluxo de caixa e a manutenção da liquidez da empresa. A ideia central é que essa gestão possibilite um encaixe cronológico entre a disposição de entrada e saída dos recursos fazendo com que a organização literalmente gire sua atividade, ou seja, funcione.

Conforme abordado por Matias (2007) a gestão do capital de giro trabalha com as contas correntes de uma organização, ou seja, aquelas realizadas e obrigadas no curto prazo. Como o custo do financiamento externo é muito alto no Brasil, a otimização dos fluxos financeiros de curto prazo tem um alto retorno marginal, o que faz com que gestores brasileiros revisem as atividades de gestão do capital de giro com grande frequência (CARVALHO; SCHIOZER, 2012).

Ao gerenciar eficientemente o capital de giro, as empresas podem reduzir sua dependência de financiamento externo e usar o caixa liberado para investimentos adicionais, melhorando a flexibilidade financeira da empresa. Além disso, por meio da gestão eficiente do capital de giro, uma empresa pode reduzir os seus custos de financiamento, uma vez que serão necessários menos recursos externos para financiar as necessidades de capital de giro (ALMEIDA, J. R.; EID Jr., 2014). 
Imagine-se um estabelecimento comercial, por exemplo uma confeitaria, montado e pronto para sua inauguração. Tem-se ali um espaço físico alocado podendo ser próprio ou alugado. Independente da natureza, despesas serão necessárias ao longo do tempo e com periodicidade, tais como aluguel, taxas, seguros, entre outros, tudo devidamente orçado no planejamento da instituição. Foram adquiridos balcões refrigerados para a empresa, bem como computadores para caixa registradora, máquinas para produção dos bolos e tortas que a empresa venha a disponibilizar. Enfim, toda uma estrutura à disposição para o funcionamento da empresa. Após isso, é necessário, literalmente, fazer a empresa girar, ou seja, colocar em prática suas operações.

É necessário também atentar-se ao financiamento que será concedido aos clientes. Segundo Lemes Junior, Cherobim e Rigo (2016), o mercado brasileiro é propício a comprar a prazo fazendo com que as contas a receber das empresas sejam alvo de investimentos consideráveis.

A gestão do capital de giro envolve então a manutenção do volume de caixa necessário para funcionamento da empresa, a decisão de estocagem tanto da ótica do custo do armazenamento como do benefício financeiro de descontos por pagamento à vista, e a gestão de contas a receber dos clientes.

Diante disso, cada empresa terá um volume diferente de recursos investidos no capital de giro. O que determinará esse volume é o modo como ela vende: se mais à vista ou a prazo, o prazo que os fornecedores concedem, o modo como paga suas contas, o tempo que leva para transformar os insumos em produtos acabados.

Diante disso, verifica-se que as contas do circulante são as que mais sofrem mutações dentro do balanço de uma empresa, justificando assim a importância de uma gestão financeira de curto prazo. Essa gestão focará continuamente as questões que envolvem a capacidade de pagamento da empresa, o fluxo de caixa e as operações nos demais itens circulantes a fim de não comprometer o giro. A figura 2 mostra como se dá o fluxo dentro do ativo circulante em uma organização.

Figura 2 - Fluxo de recursos no ativo circulante

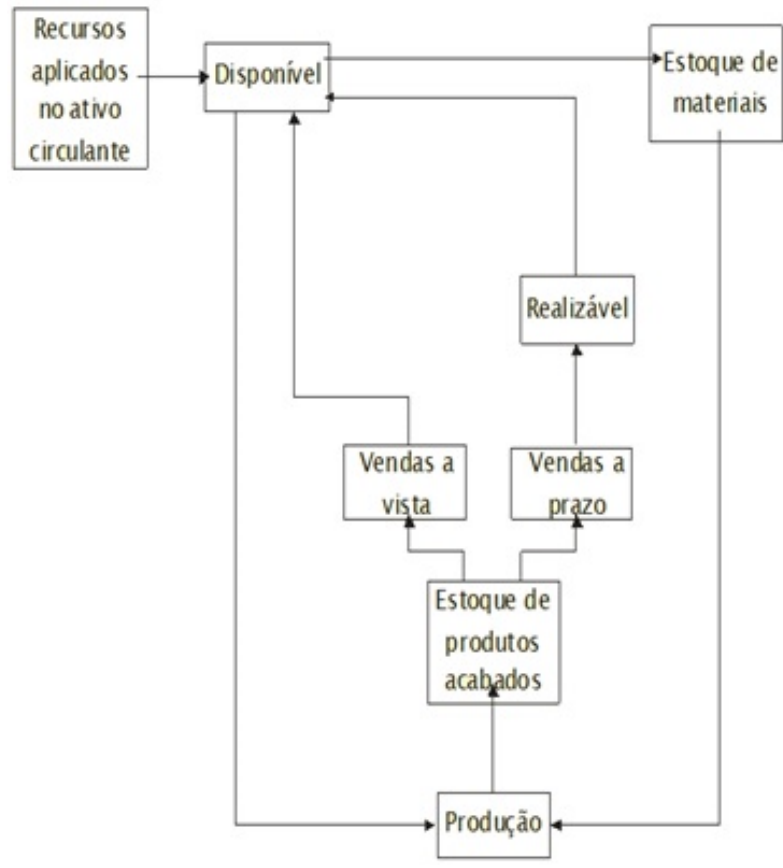

Fonte: Assaf Neto (2010, p. 555)

O capital de giro pode ser classificado como fixo e variável. Em determinadas atividades existe uma sazonalidade por demanda em seus produtos e serviços fazendo com que em determinadas épocas a empresa precise investir diferentes níveis de capital de giro de acordo com a procura (NUNN, 1981; ASSAF NETO, 2010).

Segundo os autores, o capital de giro permanente é o nível mínimo de recursos demandados pela empresa para financiar suas atividades em giro, enquanto o capital de giro sazonal é a quantidade requerida a mais para financiar as atividades da empresa em determinas épocas em função do aumento da produção e vendas da empresa, conforme a figura 3. 
Figura 3 - Capital de Giro Sazonal e Permanente

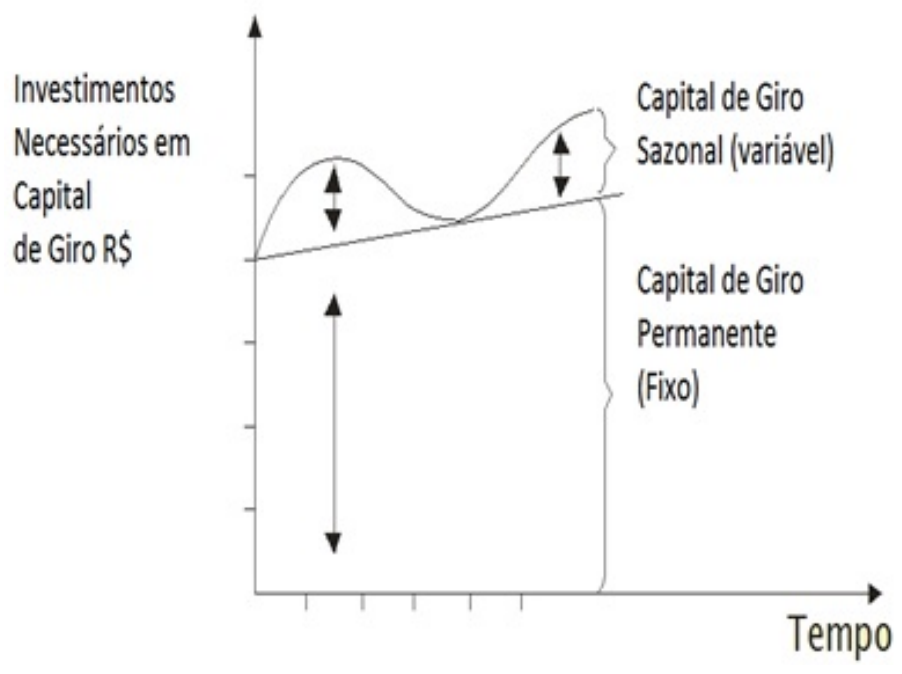

Fonte: Adaptado de Assaf Neto (2010, p. 572)

Conhecido o fluxo do ativo circulante e as características do capital de giro quanto a sua sazonalidade, por meio de mecanismos de controle de capital de giro, o administrador financeiro pode controlar e mapear o capital de giro por meio do conhecimento dos ciclos operacional e financeiro, capital circulante líquido, fontes de financiamento de capital de giro, necessidades de investimento em giro e os índices de liquidez.

\section{PROCEDIMENTOS METODOLÓGICOS}

Esta pesquisa tem caráter predominantemente quantitativo. A pesquisa quantitativa é mais indicada quando o pesquisador pretende analisar medidas quantificáveis se fundamentando em amostras da população, utilizando medidas numéricas para testar hipóteses, ou buscando padrões numéricos.

A natureza quantitativa desta pesquisa verifica-se também na exploração de variáveis mensuráveis, a partir dos dados numéricos que foram classificados e analisados, bem como a utilização de técnicas estatísticas.

O estudo enquadra-se também na pesquisa exploratória. A pesquisa exploratória tem como finalidade "proporcionar maiores informações sobre o assunto que se vai investigar; facilitar a delimitação do tema de pesquisa; orientar a fixação dos objetivos e a formulação das hipóteses" (ANDRADE, 2002, p. 19). Quanto aos fins pode ser considerada descritiva, pois descreve as informações obtidas por meio da pesquisa documental, da observação e das entrevistas.

O processo de entrevista acompanhou um modelo semiestruturado, possibilitando assim, a liberdade ao pesquisado de discorrer sobre percepções, mas também privilegiando uma orientação clara sobre tópicos e sequência da obtenção de informações desenvolvida pelos pesquisadores.

Triviños (1987) afirma que a entrevista semiestruturada valoriza ao mesmo tempo o pesquisador, por ser necessária sua lógica sequencial de exploração de informações, e também o pesquisado, por lhe permitir uma maior liberdade de resposta.

O instrumento de pesquisa adotado foi a coleta de dados. Considerou-se uma amostra não probabilística, que, de acordo com Mattar (1996, p. 132), "é aquela em que a seleção dos elementos da população para compor a amostra depende ao menos em parte do julgamento do pesquisador".

Nesta pesquisa, o universo de pesquisa está limitado às empresas do setor cerâmico catarinense associadas na ASULCER (Associação dos Produtores de Revestimento Cerâmico no Sul do Brasil) que trabalham com revestimentos. Das dez empresas existentes no Estado de Santa Catarina, oito aceitaram colaborar com a pesquisa.

Para responder ao problema de pesquisa deste trabalho, obteve-se dados primários junto aos gestores financeiros dessas empresas. Observou-se também, por meio da pesquisa realizada na empresa, algumas rotinas utilizadas em sua gestão financeira com o intuito de retratar ao máximo como funciona o dia a dia da organização.

Além das entrevistas semiestruturadas, utilizou-se de questionário com os funcionários do âmbito financeiro das organizações. Foi utilizado um questionário semiestruturado, onde o gestor financeiro respondia às questões 
propostas e, ao final, discorria sobre o que considerasse mais relevante na gestão financeira da organização que administra financeiramente.

O questionário abordou questões da gestão de curto prazo, como práticas de capital de giro, estoques, gestão de disponibilidades, gestão de crédito, relação com fornecedores, operações financeiras, aplicações de curto prazo, métodos de produção versus situação financeira, a situação da empresa em relação ao mercado, entre outros fatores.

\section{APRESENTAÇÃO E ANÁLISE DOS DADOS}

As indústrias do setor cerâmico de Santa Catarina realizam uma atividade de produção que movimenta não apenas grande quantidade de recursos financeiros, mas também de pessoas, insumos, fornecedores, caminhões e espaço físico.

Em Santa Catarina tem-se desde fábricas mais primárias onde os fornos são abastecidos a lenha para fabricação de tijolos e telhas, até os equipamentos mais modernos, movidos a gás natural. Ao visitar um parque fabril cerâmico, a primeira coisa que impressiona é a organização e a qualidade das instalações dessas indústrias.

De acordo com os entrevistados, um dos principais pontos levantados pelas empresas é o grau de endividamento assumido frente aos investimentos necessários. O principal equipamento da linha de produção é de origem italiana e faz com que a empresa não consiga fontes de financiamento no Brasil com taxas de juros atrativas. Em entrevista, um dos dirigentes afirma que um dos equipamentos custa algo em torno de 800 mil euros, e é pago semestralmente à empresa italiana, em parceria com um banco da Itália. Nota-se que, em grande parte das empresas, as parcelas de financiamento assumidas frente a estes empréstimos para comprar equipamentos acabam ocasionando muitos problemas com o caixa da organização. As empresas em sua maioria adotam controles de fluxo de caixa onde analisam a entrada e a saída dos recursos. No entanto, não são todas elas que analisam os projetos a longo prazo por meio de técnicas de análises de investimentos.

Para um melhor entendimento, em termos quantitativos e absolutos de como é feita a gestão do capital de giro destas empresas, os dados obtidos serão explicitados aqui, por meio das tabelas e gráficos gerados a partir do processamento destes resultados.

Serão apresentados os resultados quanto à utilização de políticas de capital de giro para o controle e manutenção das empresas e os mecanismos de controle apresentados na literatura que podem ser utilizados nesta gestão, tais como indicadores, índices de controle e procedimentos estratégicos como, por exemplo, a relação com fornecedores e clientes.

Conforme mostrado neste estudo, que as empresas em sua grande parte realizam planejamento de curto prazo, é interessante verificar se esse planejamento consiste também em ter diretrizes para a gestão do capital de giro, ou seja, uma política definida.

Uma política de capital de giro, de uma forma global, trata de formas de financiamento do capital de giro, procedimentos e meios adotados para operar os itens de ativo circulante e passivo circulante a fim de manter as atividades da empresa. O que deve ser feito em uma eventual falta de caixa, qual prazo e forma de pagamento que pode conceder ao seu cliente, qual compromisso pode assumir com seus fornecedores, como ofertará um produto no mercado e como manterá o nível de estoques de insumos, como cobrará os inadimplentes, o que fará com os excedentes de caixa, como financiará o capital de giro necessário, são questionamentos que podem ser respondidos por uma política de capital de giro estruturada.

A tabela 1 mostra como as empresas pesquisadas estão no que se refere às políticas de capital de giro.

Tabela 1 - Política de capital de giro

\begin{tabular}{|c|c|c|c|c|}
\hline & $\begin{array}{c}\text { Frequência } \\
\text { absoluta }\end{array}$ & $\begin{array}{c}\text { Frequência } \\
\text { absoluta } \\
\text { acumulada }\end{array}$ & $\begin{array}{c}\text { Frequência } \\
\text { relativa }\end{array}$ & $\begin{array}{c}\text { Frequência } \\
\text { relativa } \\
\text { acumulada }\end{array}$ \\
\hline Possui & 6 & 6 & $75,00 \%$ & $75,00 \%$ \\
\hline Não possui & 2 & 8 & $25,00 \%$ & $100,00 \%$ \\
\hline Não se aplica & 0 & 8 & $0,00 \%$ & $100,00 \%$ \\
\hline Total & 8 & & $100,00 \%$ & \\
\hline
\end{tabular}

Fonte: Dados primários (2015) 
Ao analisar os dados da tabela 1, percebe-se que 75\% das empresas analisam a gestão do capital de giro por meio de uma política definida. Em entrevista, constatou-se que essas políticas, em alguns casos, são informais, ou seja, existe uma série de procedimentos que são adotados ao longo do tempo, porém não se segue um protocolo. Em duas empresas estudadas existe uma espécie de manual de procedimentos a serem seguidos para a gestão do capital de giro. Esse manual de procedimentos permite manter um padrão de gestão nessas empresas. No entanto, é necessário verificar se o manual não acaba por engessar os processos da organização frente a uma dificuldade, pois ele acaba tirando de certa forma a autonomia de decisão dos gestores. Às vezes, determinada situação pode requerer uma atitude que não está prevista. Portanto, é necessário que os gestores estejam sempre avaliando essas políticas a fim de não prejudicarem suas ações nas respectivas empresas.

Constatou-se que duas empresas não possuem políticas de gestão de capital de giro. Verificou-se que são empresas administradas por sucessor familiar e pelo proprietário da empresa. Neste caso, é possível identificar que as empresas que tem um profissional contratado para fazer a gestão financeira possuem políticas de capital de giro.

Embora duas empresas não apresentem políticas definidas, percebe-se que acabam utilizando alguns desses critérios para o acompanhamento da situação do capital de giro. Não ter uma política definida não significa que a empresa não realiza gestão do capital de giro. Será apresentado seguir como elas fazem o controle dessas políticas definidas e também de suas operações com capital de giro por meio de indicadores.

Um dos controles básicos do capital de giro é a análise do período de ciclo operacional (Tabela 2). Por meio do ciclo operacional, a empresa sabe o prazo médio que leva para estocar a matéria-prima até entrar no processo produtivo, o tempo de produção, o período em que os estoques levam para serem vendidos e o prazo médio de recebimento de vendas.

Tabela 2 - Análise do período de ciclo operacional

\begin{tabular}{l|c|c|c|c}
\hline & $\begin{array}{c}\text { Frequência } \\
\text { absoluta }\end{array}$ & $\begin{array}{c}\text { Frequência } \\
\text { absoluta } \\
\text { acumulada }\end{array}$ & $\begin{array}{c}\text { Frequência } \\
\text { relativa }\end{array}$ & $\begin{array}{c}\text { Frequência } \\
\text { relativa } \\
\text { acumulada }\end{array}$ \\
\hline Analisa & 7 & 7 & $87,50 \%$ & $87,50 \%$ \\
Não analisa & 1 & 8 & $12,50 \%$ & $100,00 \%$ \\
Não se aplica & 0 & 8 & $0,00 \%$ & $100,00 \%$ \\
\hline Total & 8 & \multicolumn{5}{c}{ Fonte: Dados primários (2015) }
\end{tabular}

Pode-se verificar que $87,5 \%$ das empresas analisam o período de ciclo operacional. Em entrevista, verificou-se que apesar de analisarem estas informações, elas são apenas para conhecimento dos gestores. Não se utilizam de metas como, por exemplo, estipular um prazo padrão para o recebimento das vendas, período de produção e políticas de estocagem. Ao questionar as empresas sobre os prazos, no entanto, apenas duas têm as informações disponíveis em forma de relatório.

Gráfico 1 - Análise do período de ciclo operacional

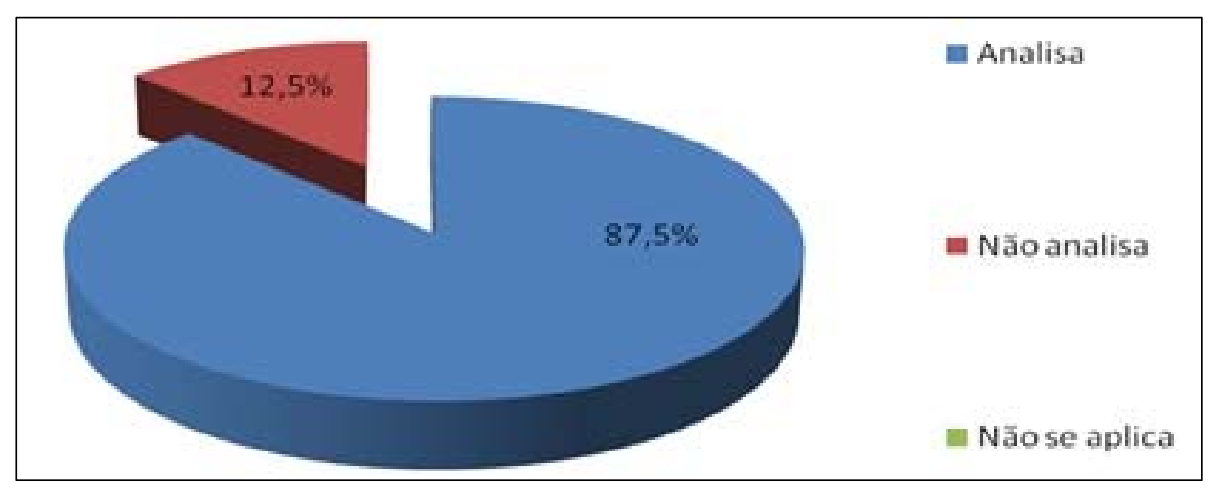

Fonte: Dados primários (2015) 
A pesquisa procurou também evidenciar quais foram estes resultados do ponto de vista financeiro. Dentre as oito empresas entrevistadas, três são sociedades anônimas e publicam seus resultados, o que facilitou a pesquisa. Os pesquisadores tiveram acesso ao balanço de mais duas empresas, e as demais informações das outras empresas foram colhidas também em entrevista. Por meio da exploração dos dados em balanço patrimonial e dos dados colhidos podese apresentar o ciclo operacional das organizações pesquisadas. Os resultados referentes aos prazos que compõe o ciclo operacional são apresentados na Tabela 3.

Tabela 3 - Índices operacionais

\begin{tabular}{c|c|c|c|c}
\hline & PMEmp & PMF & PMV & PMC \\
\hline Empresa 1 & 13,6 & 4,4 & 44,1 & 66,4 \\
Empresa 2 & 10,0 & 1,8 & 77,3 & 56,9 \\
Empresa 3 & 16,6 & 2,6 & 27,8 & 49,6 \\
Empresa 4 & 15,2 & 3,5 & 32,0 & 62,0 \\
Empresa 5 & 14,6 & 4,3 & 30,0 & 77,0 \\
Empresa 6 & 12,0 & 6,5 & 28,0 & 54,6 \\
Empresa 7 & 15,0 & 5,0 & 38,5 & 80,0 \\
Empresa 8 & 13,0 & 7,0 & 40,0 & 90,0 \\
\hline Média & 13,8 & 4,4 & 39,7 & 67,1 \\
\hline
\end{tabular}

Estes dados evidenciam como são as atividades operacionais das empresas. Pode-se concluir que o prazo médio de venda (PMV) e o período médio de cobrança (PMC) são os índices que influenciam mais no ciclo operacional da empresa.

A partir da soma desses índices pode-se observar como está o ciclo operacional das empresas pesquisadas, conforme o Gráfico 2.

Gráfico 2 - Ciclo operacional das empresas do setor cerâmico de SC

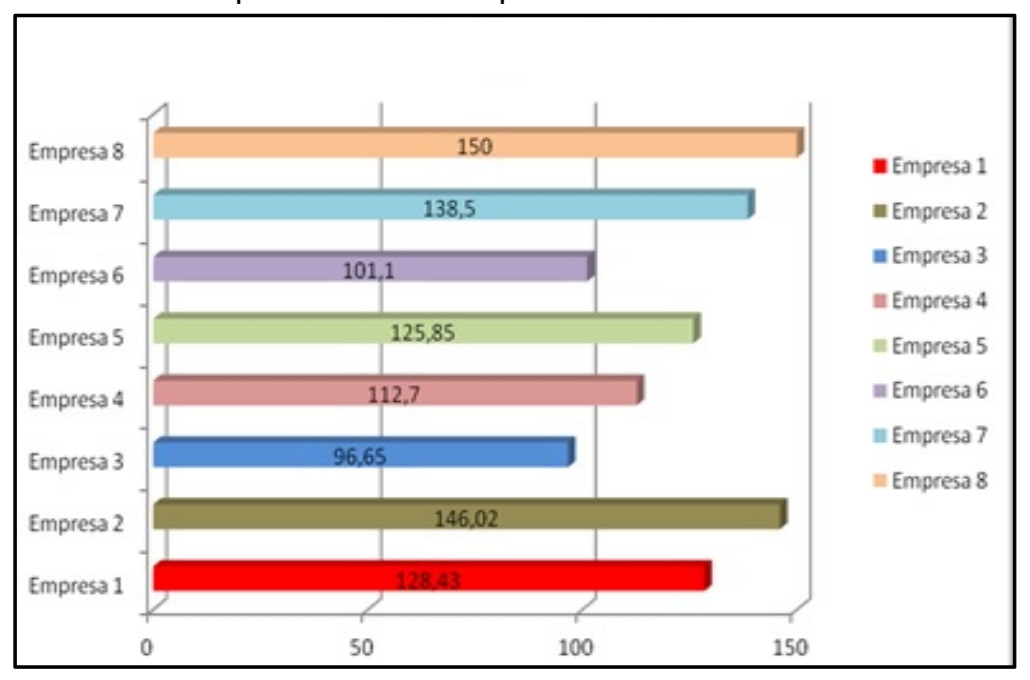

Fonte: Dados primários (2015)

De acordo com o gráfico 2, o menor ciclo operacional apresentado é o da "empresa 3", de 97 dias, sendo o único inferior a 100 dias. Seguido depois pela empresa denominada "empresa 6", com 101. Em seguida, tem-se a "empresa 4", com 113 dias. A empresa de maior ciclo operacional é a "empresa 8", com 150 dias de ciclo.

Entretanto, é preciso analisar do ponto de vista financeiro como está o ciclo de caixa dessas organizações. Para isto, precisa-se conhecer o prazo médio de pagamento aos fornecedores (PMPF) dessas empresas, apresentados na tabela 4. 
Tabela 4 - Prazo médio de pagamento a fornecedores

\begin{tabular}{l|c}
\hline & PMPF \\
\hline Empresa 1 & 98,4 \\
Empresa 2 & 66,3 \\
Empresa 3 & 42,9 \\
Empresa 4 & 76,5 \\
Empresa 5 & 69,3 \\
Empresa 6 & 55,4 \\
Empresa 7 & 35,8 \\
Empresa 8 & 73,8 \\
\hline \multicolumn{2}{l}{} \\
\hline
\end{tabular}

Fonte: Dados primários (2015)

O PMPF apresenta uma média de 65 dias, de acordo com os dados da tabela 4. A empresa que obtém o maior prazo é a empresa um com 98 dias. A "Empresa 7", por sua vez, apresenta o menor prazo recebido, com o índice de 36 dias.

Ao calcular o ciclo operacional e descontar o prazo médio de pagamento dos fornecedores encontra-se o ciclo de caixa. O ciclo de caixa ou ciclo financeiro indica o período necessário em que a empresa precisa fomentar suas operações ou o período em que os recursos ficam disponíveis para operação. As empresas adotam a ferramenta conforme a tabela 5 .

Tabela 5 - Análise do ciclo de caixa

\begin{tabular}{l|c|c|c|c}
\hline & $\begin{array}{c}\text { Frequência } \\
\text { absoluta }\end{array}$ & $\begin{array}{c}\text { Frequência } \\
\text { absoluta } \\
\text { acumulada }\end{array}$ & $\begin{array}{c}\text { Frequência } \\
\text { relativa }\end{array}$ & $\begin{array}{c}\text { Frequência } \\
\text { relativa } \\
\text { acumulada }\end{array}$ \\
\hline Analisa & 3 & 3 & $37,50 \%$ & $37,50 \%$ \\
Não analisa & 5 & 8 & $62,50 \%$ & $100,00 \%$ \\
Não se aplica & 0 & 8 & $0,00 \%$ & $100,00 \%$ \\
\hline Total & 8 & \multicolumn{5}{c}{ Fonte: Dados primários (2015) }
\end{tabular}

Apesar de 87,5\% procurar analisar o ciclo operacional, apenas 37,5\% analisa o ciclo financeiro. O principal motivo disto é o fato das empresas submeterem-se aos prazos dos fornecedores e de muitos clientes que desejam pagar conforme suas necessidades e as empresas aceitam, pois precisam realizar vendas e manter um nível de receitas a fim de saldar seus compromissos assumidos. Nas entrevistas verificou-se que todas as empresas, sem exceção, possuem um descompasso entre os recebimentos e os pagamentos, tendo então um ciclo de caixa desfavorável.

A partir da subtração do ciclo operacional pelo PMPF obteve-se os ciclos financeiros dessas empresas, apresentados no gráfico 3.

Constata-se que nenhuma empresa do setor cerâmico catarinense tinha um ciclo de caixa favorável, ou seja, todas elas pagam seus custos aos fornecedores antes de receber os recursos provenientes das vendas de seus produtos. $\mathrm{A}$ média obtida foi de 60 dias. Merece destaque a "empresa 7" que apresentou 103 dias de ciclo financeiro, superando em mais de 40 dias a média das empresas pesquisadas. A "empresa 1", no entanto, é a que possui o menor ciclo financeiro 30 dias. 


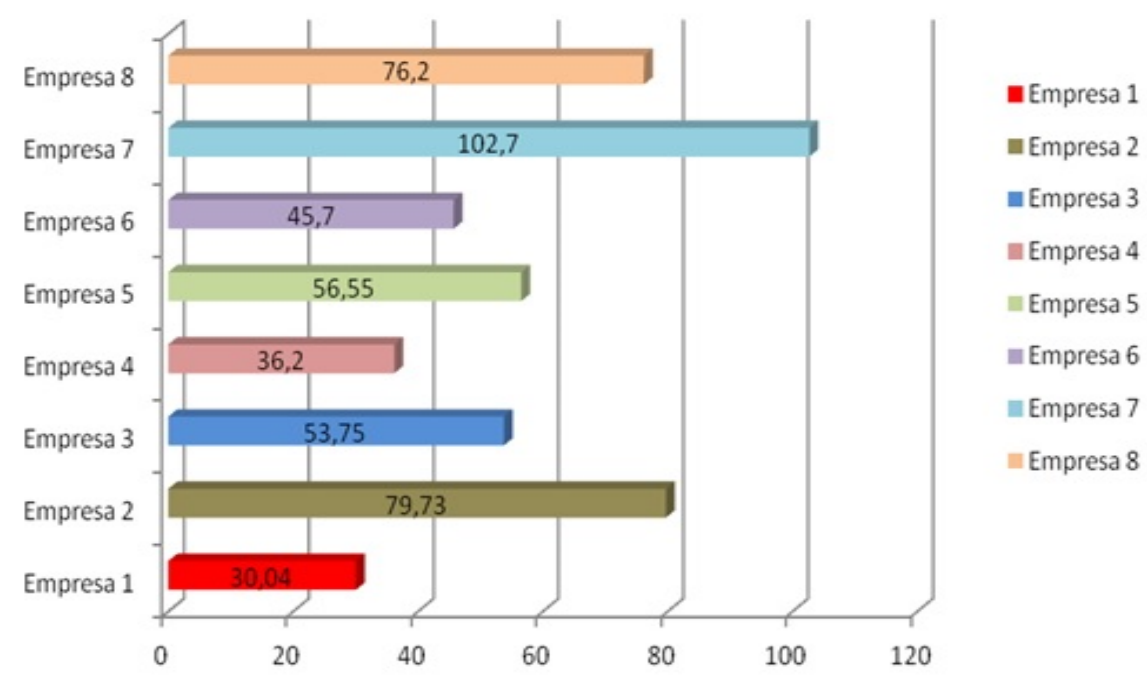

Fonte: Dados primários (2015)

Muitos custos poderiam ser reduzidos se as empresas estipulassem metas tanto no ciclo operacional como no financeiro, pois ao reduzir este prazo significa que as empresas têm a capacidade de movimentar sua atividade com os recursos alocados em estoques, contas a receber juntamente com as fontes de financiamento de curto prazo, evitando assim um alto investimento em valores em caixa. O caixa pode ser depreciado pela inflação e é o ativo menos rentável dentro de uma empresa, mas em contrapartida oferece segurança ao realizar a manutenção da liquidez da empresa.

A liquidez, por sua vez, é algo que deve ser constantemente analisado a fim de verificar a capacidade de pagamento das empresas. A utilização deste índice é dada na Tabela 6 .

Tabela 6 - Utilização dos índices de liquidez

\begin{tabular}{l|c|c|c|c}
\hline & $\begin{array}{c}\text { Frequência } \\
\text { absoluta }\end{array}$ & $\begin{array}{c}\text { Frequência } \\
\text { absoluta } \\
\text { acumulada }\end{array}$ & $\begin{array}{c}\text { Frequência } \\
\text { relativa }\end{array}$ & $\begin{array}{c}\text { Frequência } \\
\text { relativa } \\
\text { acumulada }\end{array}$ \\
\hline Analisa & 6 & 6 & $75,00 \%$ & $75,00 \%$ \\
Não analisa & 2 & 8 & $25,00 \%$ & $100,00 \%$ \\
Não se aplica & 0 & 8 & $0,00 \%$ & $100,00 \%$ \\
\hline Total & 8 & \multicolumn{5}{|c}{ Fonte: Dados primários (2015) }
\end{tabular}

Conclui-se que 75\% das empresas utilizam indicadores de liquidez. Ainda em entrevista com as que não utilizam, as mesmas revelaram que não utilizam o indicador, pois apesar de terem problemas com caixa sempre conseguem captar recursos para cobrir esta necessidade. Ao questionar as empresas que usam o controle constatou-se que utilizam muito da liquidez imediata (apenas o caixa) e da liquidez seca, e que não consideram os estoques. Três das empresas utilizam relatórios completos, os quais mostram os índices e sua evolução ao longo dos anos, porém não existe um nível de liquidez determinado no planejamento que deve ser alcançado ou mantido.

Frente a não determinação de um índice ideal do mercado cerâmico catarinense, apresenta-se a seguir os índices de liquidez das empresas pesquisadas. Para melhor visualização, apresenta-se cada índice no gráfico 4. 
Gráfico 4 - Liquidez das empresas setor cerâmico catarinense
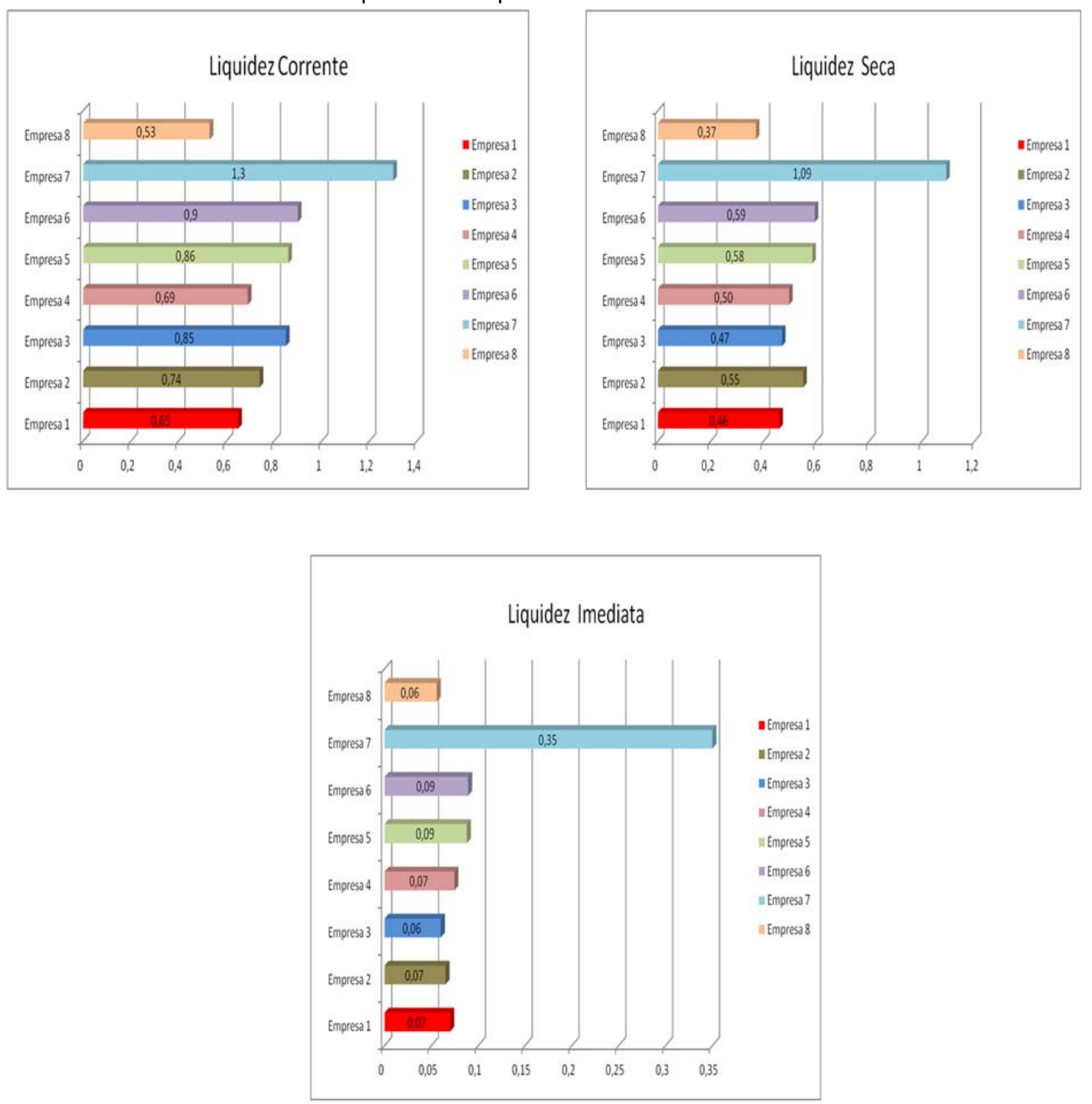

Fonte: Dados primários (2015)

Constata-se que apenas a "empresa 7" apresenta um índice de liquidez corrente superior a 1, ou seja, é a única empresa teoricamente capaz de saldar seus compromissos de curto prazo com recursos do ativo circulante. Este índice também simplifica um pouco as análises. Uma empresa só pode apresentar capital circulante liquido (CCL) positivo caso sua liquidez seja maior que 1 . No caso das indústrias do setor cerâmico catarinense, verifica-se que sete das oito empresas entrevistadas possuem um passivo circulante maior que o ativo circulante levando-nos a concluir então que $87,5 \%$ das empresas pesquisadas apresentam um CCL negativo.

Outro ponto que pode ser destacado também é que as empresas alocam recursos de curto prazo em ativos de longo prazo. Uma vez que existe uma dívida de curto prazo e os recursos não se equalizam em ativos circulantes, o destino deles são aplicações de longo prazo o que compromete a capacidade de pagamento da empresa.

No entanto, conforme abordado na pesquisa, as empresas dão mais atenção para os índices de liquidez imediata e seca, que por sua vez é um índice que exclui do cálculo as contas de despesas antecipadas e estoques do ativo circulante para o cálculo da liquidez. Estatisticamente, a capacidade de pagamento das empresas caiu em média $29 \%$ ao não considerar os estoques. No entanto, a "empresa 7" ainda apresenta capacidade superior a 1, o que significa dizer que não precisa vender seus estoques para honrar seus compromissos. Nota-se, também que as empresas ficaram de certa forma dentro da mesma faixa de liquidez, com índices de 0,46 até 0,59, com exceção da "empresa 8" que ficou com liquidez de 0,37. 
Analisando a liquidez imediata que é um índice que reflete a capacidade de pagamento dos compromissos de curto prazo frente às disponibilidades da organização, verifica-se que no curto prazo as empresas não podem apenas contar com o seu caixa para honrar seus compromissos. A apresentação desses dados também evidencia possíveis problemas de caixa nas organizações, uma vez que se aproximam de zero. Percebe-se também que as empresas precisam operar recebíveis em sua totalidade e vender estoques para honrar as contas, ou, de forma mais cara, captar empréstimos.

Complementando ainda as informações sobre o nível de produção e vendas da empresa, questionou-se os gestores sobre a utilização de análise do valor do ativo operacional e do passivo operacional. A partir disto, foi analisado se a empresa verifica a necessidade de investimento em capital de giro. Os resultados estão apresentados na Tabela 7.

Tabela 7 - Análise do ativo circulante operacional

\begin{tabular}{|c|c|c|c|c|}
\hline & $\begin{array}{c}\text { Frequência } \\
\text { absoluta }\end{array}$ & $\begin{array}{c}\text { Frequência } \\
\text { absoluta } \\
\text { acumulada }\end{array}$ & $\begin{array}{c}\text { Frequência } \\
\text { relativa }\end{array}$ & $\begin{array}{c}\text { Frequência } \\
\text { relativa } \\
\text { acumulada }\end{array}$ \\
\hline Analisa & 7 & 7 & $87,50 \%$ & $87,50 \%$ \\
\hline Não analisa & 1 & 8 & $12,50 \%$ & $100,00 \%$ \\
\hline Não se aplica & 0 & 8 & $0,00 \%$ & $100,00 \%$ \\
\hline Total & 8 & & $100,00 \%$ & \\
\hline
\end{tabular}

Verifica-se que $87,5 \%$ das empresas analisam o ativo circulante operacional, a fim de manter uma boa saúde financeira do ativo circulante. 0 gráfico 5 ilustra os dados obtidos.

Gráfico 5 - Análise ativo circulante operacional

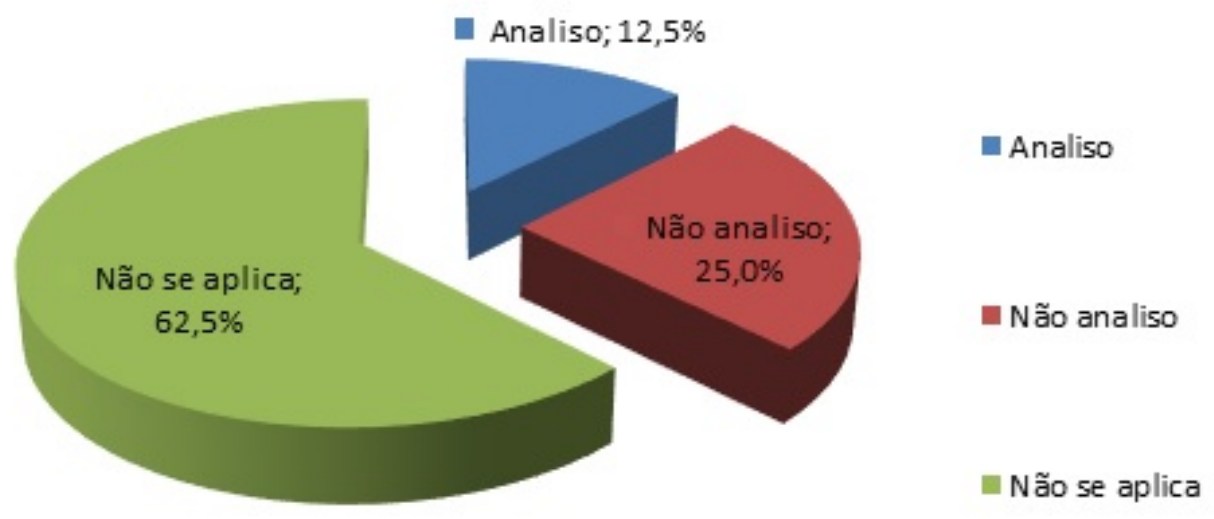

Fonte: Dados primários (2015)

Como esperado, as empresas realizam a análise em números exatamente iguais para o passivo circulante operacional, pois a análise de ambos é essencial para o efetivo controle dessas contas no balanço patrimonial da empresa.

Tabela 8 - Análise do passivo circulante operacional

\begin{tabular}{l|c|c|c|c}
\hline & $\begin{array}{c}\text { Frequência } \\
\text { absoluta }\end{array}$ & $\begin{array}{c}\text { Frequência } \\
\text { absoluta } \\
\text { acumulada }\end{array}$ & $\begin{array}{c}\text { Frequência } \\
\text { relativa }\end{array}$ & $\begin{array}{c}\text { Frequência } \\
\text { relativa } \\
\text { acumulada }\end{array}$ \\
\hline Analisa & 7 & 7 & $87,50 \%$ & $87,50 \%$ \\
Não analisa & 1 & 8 & $12,50 \%$ & $100,00 \%$ \\
Não se aplica & 0 & 8 & $0,00 \%$ & $100,00 \%$ \\
\hline Total & 8 & \multicolumn{5}{c}{ Fonte: Dados primários (2015) }
\end{tabular}


Com esta análise pode se verificar se as empresas calculam a necessidade de investimentos em capital de giro. Esperava-se que todas as empresas que analisam ativos e passivos circulantes operacionais chegassem a calcular os índices, porém a proporção não se manteve, conforme os dados do gráfico 6.

Gráfico 6 - Análise ativo circulante operacional

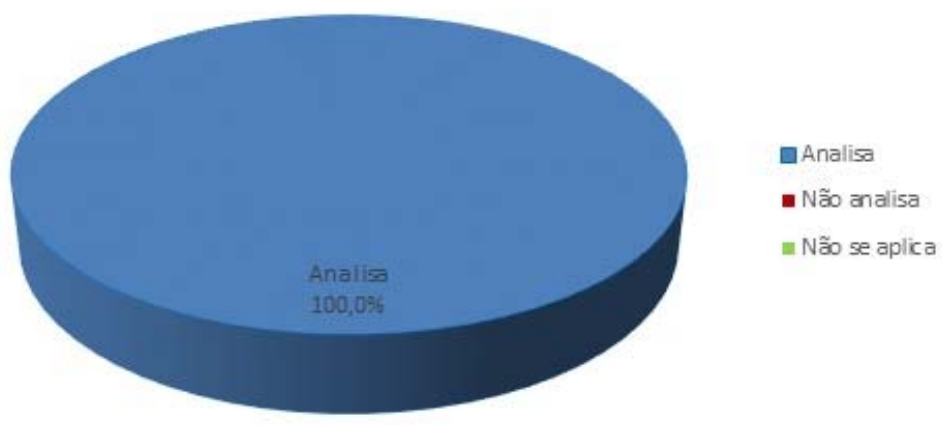

Fonte: Dados primários (2015)

Isso leva a concluir que $12,5 \%$ das empresas que analisam os ativos e passivos circulantes operacionais não aproveitam essas informações, pois por meio de sua diferença poderiam calcular a necessidade de investimento em capital de giro.

Questionou-se, quanto ao capital de giro, se as empresas calculam o Capital Circulante Líquido (CCL) a fim de verificar a diferença entre os ativos e passivos circulantes da empresa. As empresas utilizam, em sua totalidade, o cálculo de capital circulante líquido para verificar como está o capital de giro líquido da organização.

Gráfico 7 - Análise do capital circulante líquido

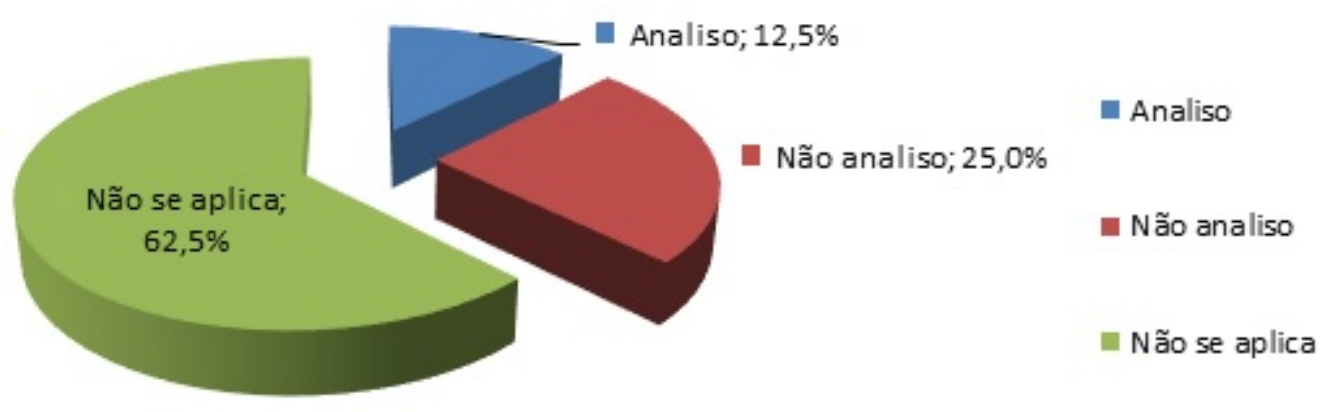

Fonte: Dados primários (2015)

Por último, buscou-se compreender como as empresas planejam as fontes de financiamento do capital de giro da empresa, pois deve existir um equilíbrio entre as fontes de financiamento e os investimentos no que diz respeito ao prazo (BANOS-CABALLERO; GARCIA-TERUEL; MARTINEZ-SOLANO, 2010). Sabe-se que recursos de curto prazo devem financiar itens de curto prazo. Ainda se deve considerar o capital de giro sazonal e o capital de giro variável, questionou-se, então, às empresas se analisam o capital de giro sazonal e o capital de giro variável. Conforme relatos das entrevistas com os dirigentes, o segundo semestre do ano é sempre o mais aquecido da indústria, enquanto que nos meses de janeiro e fevereiro as receitas diminuem, porém ao questionamento sobre como é feito o cálculo do capital de giro permanente e variável obteve-se os resultados conforme o Gráfico 8. 
Gráfico 8 - Cálculo do capital de giro permanente e sazonal

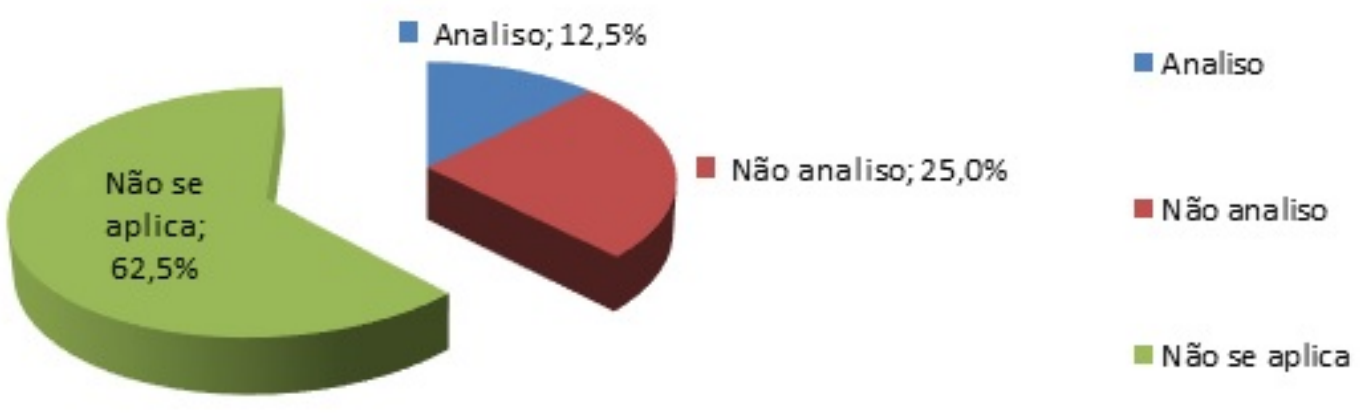

Fonte: Dados primários (2015)

Constatou-se que apenas uma empresa realiza este cálculo. Outras 62,5\% não realizam o cálculo e, complementando a totalidade, outras 37,5\% dizem desconhecer estes cálculos.

O financiamento dessas necessidades quanto à abordagem de financiamento é apresentado conforme a tabela 9.

Tabela 9 - Abordagem do financiamento do capital de giro

\begin{tabular}{l|c|c|c|c}
\hline & $\begin{array}{c}\text { Frequência } \\
\text { absoluta }\end{array}$ & $\begin{array}{c}\text { Frequência } \\
\text { absoluta } \\
\text { acumulada }\end{array}$ & $\begin{array}{c}\text { Frequência } \\
\text { relativa }\end{array}$ & $\begin{array}{c}\text { Frequência } \\
\text { relativa } \\
\text { acumulada }\end{array}$ \\
\hline Risco mínimo & 0 & 0 & $0,00 \%$ & $0,00 \%$ \\
Equilíbrio financeiro tradicional & 0 & 0 & $0,00 \%$ & $0,00 \%$ \\
Sem abordagem & 7 & 7 & $87,50 \%$ & $87,50 \%$ \\
Outros & 1 & 8 & $12,50 \%$ & $100,00 \%$ \\
\hline Total & 8 & & $100,00 \%$ & \\
\hline
\end{tabular}

Fonte: Dados primários

As empresas, em sua maioria, não utilizam abordagens de financiamento do capital de giro devido ao fato de precisarem constantemente de capital de empréstimos para financiar suas necessidades. Desta forma, as empresas acabam por optar sempre por aquele capital que é ofertado de forma mais barata e dentro das possibilidades de captação da empresa. Uma empresa utiliza uma outra maneira que é a de financiar o capital de giro integralmente com capital próprio devido a seu lastro financeiro. Ao cruzar os dados, verificou-se que esta empresa não tem políticas de capital de giro definidas. Ela deveria traçar metas e controles a fim de investir recursos próprios em ativos circulantes mais rentáveis e tentar fomentar o capital de giro por meio de fornecedores, por exemplo, o que poderia potencializar seus resultados, uma vez que a taxa cobrada pelo fornecedor para vender a prazo provavelmente é menor do que o retorno produzido por aplicações em ativos de longo prazo em um mercado onde a demanda é crescente e a produção interna não tem capacidade de suprir o que o mercado vem exigindo.

\section{CONSIDERAÇÕES FINAIS}

Após a apresentação dos resultados, por meio da elaboração e aplicação da pesquisa, bem como o tratamento dos dados e visando responder como é a gestão financeira praticada com relação à teoria apresentada e também a comparação de indicadores de curto prazo com a empresa adotada como referência para o setor, esta seção contém as considerações acerca do tema pesquisado respondendo a problemática proposta no estudo.

Existem três casos expressivos de falência no Estado de Santa Catarina no setor cerâmico aqui estudado: caso da Cerâmica Vectra, DeLucca e Tec-Cer. No entanto, não foi possível entrevistar dirigentes destas empresas a fim de verificar qual o perfil do gestor financeiro destas para se verificar a relação entre sua formação e o insucesso destas organizações. 
O estudo revelou que $75 \%$ das empresas têm definidas suas políticas de capital de giro, porém, do total de empresas, apenas $12,5 \%$ têm isto definido como um procedimento a ser seguido. Ainda, constatou-se que em sua totalidade as empresas utilizam ferramentas de administração do capital de giro.

Dentre o ferramental da análise do capital de giro, foi constatado que as empresas utilizam, em sua maioria, a análise do ciclo operacional e do ciclo financeiro. Outro ponto a ser analisado são os dados obtidos quanto à gestão do capital de giro com relação ao setor pesquisado.

Constata-se que o ciclo operacional médio do setor cerâmico catarinense é de 125 dias. 0 prazo médio de pagamento a fornecedores é de 65 dias, fazendo então com que o ciclo financeiro médio das organizações seja de 60 dias.

Apesar de apresentar um ciclo financeiro médio de 60 dias, algumas empresas apresentam valores até 71,17\% maiores nesse período, enquanto o limite inferior é de 49,93\% menor que a média.

Nota-se, neste caso, que $62,5 \%$ das empresas encontram-se abaixo da média do setor, enquanto as demais encontram-se acima. Devido ao fato de muitos gestores afirmarem ter problemas com o financiamento do capital de giro, conforme mostrado na pesquisa, e precisarem, constantemente, de financiamentos bancários e antecipação de recebíveis para honrar os seus compromissos, sugere-se aqui que as empresas prestem mais atenção nos índices que compõe o ciclo operacional.

No entanto, quanto à produção verificou-se que as empresas têm procedimentos organizados e com equipamentos de última geração, levando a crer que este índice está próximo ao ideal quanto ao seu funcionamento. No entanto, o período médio de estocagem desta matéria-prima deve ser reduzido, pois iria contribuir diretamente para a redução do ciclo financeiro. Percebe-se um descompasso entre a fabricação e a venda. Nota-se que o prazo médio nos estoques, em relação ao período médio de fabricação, é muito alto, chegando a ser até de 40 dias.

Em relação ao prazo de recebimento de venda, é algo que deve ser considerado do ponto de vista não só financeiro, mas também comercial. Segundo os gestores entrevistados, a realidade atual de demanda do mercado é muito maior que a capacidade produtiva no Brasil, ainda mais que grande fatia, conforme mostrado na caracterização do setor, abastece o mercado externo.

De acordo com as características de estrutura de mercado apresentadas por Mankiw (2014), o setor cerâmico é considerado um oligopólio diferenciado, ou seja, poucas e grandes firmas dominam um setor, no qual a concorrência se dá via diferenciação, embora os preços também sejam importantes.

Com isso, as empresas acabam importando produtos da China com qualidade a preços atraentes abastecendo o mercado. Com esta parceria, a capacidade produtiva não se torna mais tanto um fator competitivo em termos de preço e sim de diferenciação. Porém, o preço e o prazo de pagamento são ditados pelo mercado, uma vez que o setor cerâmico está diretamente atrelado ao comportamento do setor da construção civil. Aumentar o prazo de pagamento do cliente não significa que as empresas venderão mais, uma vez que o mercado está limitado pela demanda da construção civil. Neste caso, analisa-se que a política de crédito, apesar de muito importante, no ponto de vista financeiro, perde um pouco de validade no sentido em que seus efeitos não impactam de forma tão agressiva no volume de vendas. $O$ interessante neste caso é que a empresa tente trabalhar o relacionamento com seus clientes para diminuir este prazo de recebimento e, por consequência, a diminuição de seu ciclo financeiro.

Por último, verifica-se que as empresas do setor cerâmico de Santa Catarina também devem trabalhar o seu relacionamento com os fornecedores a fim de estabelecer prazos de pagamento mais alongados. No entanto, isso dever ser feito de forma a analisar o custo (taxa de juros) cobrado pelo fornecedor ao conceder mais prazo para as empresas. Sugere-se neste caso que a empresa além de comparar o custo do dinheiro do fornecedor versus sua fonte de financiamento, deve levar em conta o impacto gerado no ciclo financeiro. Conforme apresentado nas pesquisas, as empresas não se utilizam de métodos para análise dos custos de oportunidade em estoques, devendo então analisar o custo destes recursos ao longo do tempo em uma gestão financeira de estoques mais apurada.

Quanto à liquidez das empresas, foi constatado que as organizações se utilizam desses índices, porém não existe uma comparação ou um índice de referência a ser comparado. A liquidez, no entanto, é utilizada para fins históricos e acompanhamento da evolução das empresas.

Constatou-se que as empresas apresentam uma gestão de capital de giro planejada, executada por gestores competentes com diretrizes pouco definidas. Porém, com uma gestão que utiliza o ferramental teórico disponível, com indicadores financeiros com relação à capacidade de pagamento não saudáveis de uma maneira geral, assim como os indicadores operacionais com certa homogeneidade.

A utilização dos índices deve ser feita para acompanhamento e mudança nos padrões das empresas e não apenas para fins históricos, conforme apresentado, o que irá auxiliar as empresas a enfrentarem possíveis dificuldades. 


\section{REFERÊNCIAS}

ALMEIDA, J. R.; EID Jr., W. Access to finance, working capital management and company value: evidences from Brazilian companies listed on BM\&FBOVESPA, Journal of Business Research, v. 67, p. 924-934, 2014.

ANDRADE, M. M. Como preparar trabalhos para cursos de pós-graduação: noções práticas. 5. ed. São Paulo: Atlas, 2002.

ASSAF NETO, Alexandre. Finanças corporativas e valor. São Paulo: Atlas. 2010.

BANOS-CABALLERO, S.; GARCIA-TERUEL, P. J.; MARTINEZ-SOLANO, P. Working capital management in SMEs, Accounting and Finance, v. 50, p. 511-527, 2010.

CARVALHO, C. J.; SCHIOZER, R. F. Gestão de capital de giro: um estudo comparativo entre práticas de empresas brasileiras e britânicas, RAC, Rio de Janeiro, v. 16, n. 4, p. 518-543, jul./ago. 2012.

HOWORTH, C.; WESTHEAD, P. The focus of working capital management in UK small firms, Management Accounting Research, v. 14, n. 2, p. 94-111, 2003.

KROES, J. R.; MANIKAS, A. S. Cash flow management and manufacturing firm financial performance: a longitudinal perspective, Int. J. Production Economics, v. 148, p. 37-50, 2014.

LEMES Jr, A. B.; CHEROBIM, A. P.; RIGO, C. M. Administração financeira: princípios, fundamentos e práticas brasileiras. 4. ed. Rio de Janeiro: Campus, 2016.

MANKIW, N. G. Introdução a economia. 6. ed. São Paulo: Cengage Learning, 2014.

MARION, J. C. Contabilidade empresarial. 17. ed. São Paulo: Atlas, 2015.

MATIAS, A. B. (Org.) Finanças corporativas de curto prazo. São Paulo: Atlas, 2006.

MATTAR, F. N. Pesquisa de marketing: metodologia, planejamento, execução, análise. 2. ed. São Paulo: Atlas, 1996.

MODIGLIANI, F.; MILLER, M. H. The cost of capital, corporation finance and the theory of investment, American Economic Review, v. 48, n. 3, p. 261-297, 1958.

NUNN, K. P. The strategic determinants of working capital: a product-line perspective. The Journal of Financial Research, v. 4, n. 3, p. 207-219, 1981.

PALOMBINI, N. V. N.; NAKAMURA, W. T. Key factors in working capital management in the brazilian market, RAERevista de Administração de Empresas, v. 52, n. 1, p. 55-69, jan./fev. 2012.

ROSS, S.A.; WESTERFIELD, R.W.; JAFFE, J.F. Administração financeira. São Paulo: Atlas, 2007.

SANTOS, J. O. Análise de crédito: empresas, pessoas físicas, agronegócio e pecuária. 3. ed. São Paulo: Atlas, 2010.

SEBRAE - Sistema Brasileiro de Apoio às Micro e Pequenas Empresas. Fatores condicionantes e taxas de sobrevivência e mortalidade das micro e pequenas empresas no Brasil 2003-2005. Brasília, DF, 2007.Disponível em:

<http://www.bibliotecas.sebrae.com.br/chronus/ARQUIVOS_CHRONUS/bds/bds.nsf/8F5BDE79736CB99483257447006 CBAD3/\$File/NT00037936.pdf>. Acesso em: 05 abr. 2017.

TRIVIÑOS, A. N. S. Introdução à pesquisa em ciências sociais: a pesquisa qualitativa em educação. São Paulo: Atlas, 1987.

VIEIRA, Marcos Vilela. Administração estratégica do capital de giro. São Paulo: Atlas, 2005. 